\title{
¿DISMINUYE EL DESFLURANO LA ESTADÍA POSTOPERATORIA EN CIRUGÍA BARIÁTRICA EN COMPARACIÓN AL SEVOFLURANO? ANÁLISIS CON PROPENSITY SCORES
}

\author{
Ojeda Dagoberto ${ }^{1}$, López Sebastián ${ }^{2}$, Cisternas Patricia ${ }^{3}$ \\ Anestesiólogo Clínica Dávila. \\ Médico pasantía Anestesiología Universidad de los Andes-Clínica Dávila. \\ Jefatura anestesiología Clínica Dávila.
}

Introducción: La obesidad se asocia a comorbilidades que hacen conveniente un rápido despertar de la anestesia ${ }^{1}$. El Desflurano se carateriza por un bajo coeficiente de solubilidad grasa/sangre $^{2}$ lo que en teoría sería ventajoso en este tipo de pacientes pero la evidencia no ha demostrado una clara superioridad sobre el Sevoflurano ${ }^{3}$.

Objetivo General: Se investigará la siguiente hipótesis: Si el Desflurano es beneficioso en pacientes obesos; debería acortar la estadía postoperatoria en cirugía bariátrica en relación al Sevoflurano.

Material y Métodos: Se realizó un estudio observacional retrospectivo. Se revisaron los registros de los pacientes sometidos a cirugía bariátrica durante los años 2012-2013-2014. Se

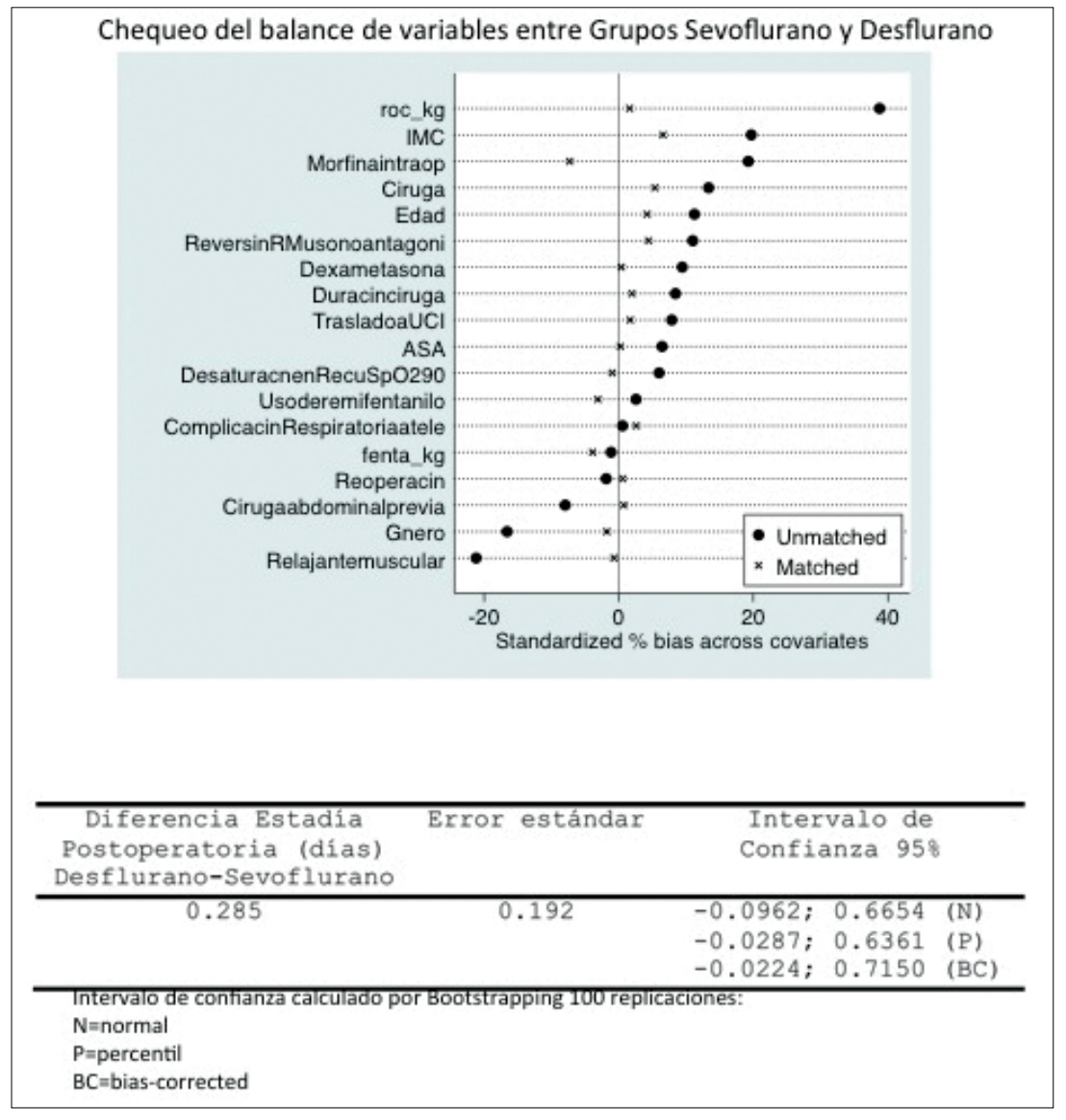

Figura 1. 
consignaron las características demográficas basales, drogas anestésicas, tipo y duración de la cirugía, presencia de complicaciones quirúrgicas, anestésicas, postoperatorias, traslado a UCI y reoperación. Para aproximarse a la obtención de efectos causales y soslayar el sesgo de confusión se utilizaron propensity scores (PS), calculados mediante regresión logística en base a todas aquellas variables asociadas a la elección del halogenado y del outcome. Se realizó el matching y chequeo del balance del sesgo en la submuestra con diferencia estandarizada de medias. Una vez asegurado el balance se verificó si existía un efecto significativo del Desflurano en la duración de la estadía postoperatoria a través del método de matching de Kernel. Los análisis se realizaron en STATA 13.

Resultados: Se obtuvo información de 1.130 pacientes: 410 pacientes anestesiados con Sevoflurano y 720 con Desflurano. El grupo Desflurano tenía significativamente una mayor proporción de hombres, mayor IMC, mayor proporción de bypass gástrico, duración más prolongada de la cirugía y uso de mayores dosis de rocuronio. Al realizar el matching con propensity scores se obtuvo una submuestra de 1.081 pacientes: 389 (Sevoflurano) y 692 (Desflurano). Se logro un buen balance entre los grupos en estudio evidenciado por una disminución del sesgo (promedio) desde $8,9 \%(p=0,000)$ a $1,87 \%(p=0,996)$. En esta submuestra la duración de la estadía postoperatoria para Desflurano fue de 4,3 $\pm 3,3$ días y para Sevoflurano de $4,0 \pm 2,3$ días. La diferencia entre la duración de las estadías era $\mathrm{NO}$ SIGNIFICATIVA, tanto al analizarla por t-test: $\Delta$ $=0,285 ; \mathrm{p}=0,137$ como por método de Kernel: $\Delta=0,285$; Int Confianza 95\% $=[-0,1 ; 0,7]$.

Conclusiones: Pese a los efectos beneficiosos teóricos del Desflurano en pacientes obesos, este no demostró una disminución en la estadía postoperatoria de cirugía bariátrica al compararlo con Sevoflurano. Si no hay evidencia demostrada de las ventajas del Desflurano: ¿Se justificaría utilizarlo si es más costoso?

\section{Referencias}

1. Ahmad S. Postoperative hypoxemia in morbidly obese patients with and without sleep apnea undergoing laparoscopic bariatric surgery. Anesth Analg 2008; 107:138-43.

2. Patel SS. Desflurane. A review of its pharmacodynamics and pharmacokinetics properties and its efficacy in general anesthesia. Drugs 1995; 50: 742-67.

3 Kaur A. Hemodynamics and early recovery characteristics of desflurane and sevoflurane in bariatric surgery. J Anesthesiol Clin Pharmacol 2013; 36-49. 